\title{
The Effect of a Simple Reward Model on the Academic Achievement of Syrian Dental Students
}

\author{
Aous Dannan ${ }^{1}$
}

\section{ARTICLE INFO}

Article History:

Received 10.11.2019

Received in revised form

09.06.2020

Accepted

Available online 01.10 .2020

\begin{abstract}
Reward systems in teaching are important keys which aim at enhancing students' academic achievements. Studying the effects of rewards, as extrinsic motivators, on college students is somehow underestimated in the literature. The aim of the current study was to investigate the effect of a simple tangible reward on the academic achievement of Syrian dental students. A total of 139 dental students, assigned to four classes, were enrolled in the study. After completion of a first exam, all students who got full marks (i.e. 20 marks) were awarded a "Certificate of Achievement". Four weeks later, a second exam related to the same course took place, and the same process of certification for students with full marks was performed. Records of students' marks of both first and second exams were collected and statistically analyzed. The results showed no statistically significant differences between groups (i.e. classes) neither for first exam nor for second exam marks. The mean of marks for the first and second exams were (10.62 \pm 4.88$)$ and $(14.63 \pm 4.07)$ respectively. The difference of means' records for all students between first and second exams was statistically significant. It was concluded that a tangible reward in the form of "certificate" had a positive effect on the dental students' academic achievements. Enhancement of students' motivation through reward systems should come under focus in higher educational institutions.
\end{abstract}

(C) IJERE. All rights reserved

Keywords: ${ }^{1}$

Reward, dental student, motivation, academic achievement.

\section{INTRODUCTION}

Poor student achievement is often attributed to a lack of motivation, and rewards are usually given in an attempt to increase the vital student motivation. High student achievement comes from students who are motivated from inside. Therefore, besides giving rewards, teachers need to consistently teach students to become intrinsically motivated (Baranek 1996).

In the 1970's, Edward Deci (Deci 1971, 1972b, 1972a) defined the different kinds of motivation as intrinsic motivation and extrinsic motivation, intrinsic motivation is the act of completing an activity for the pleasure of doing the activity itself. Extrinsic motivation, on the other hand, is the act of completing an activity in order to receive some type of reward from another source. As a result of these definitions, researchers began to question the effects of different kinds of motivation, and school became a widely used testing ground.

In research conducted during the last years, it has been found that intrinsic and extrinsic motivation have different effects on education. The presence of intrinsic motivation produces many behaviors that result in school success like sustained interest in tasks, risk taking, and the conquering of new challenges (Amabile and Gitomer 1984; Adelman and Taylor 1990; Spulding 1992). External motivators are things given to the students by others like grades, candy, free time, and other things. Students who are motivated by extrinsic factors complete activities in order to receive an external reward (Scott Jr 1976). As a result, they do not work out events on their own, but work only to receive a reward. However, a reward that is received after successful completion of a task without previous expectancy could have a positive effect on future related tasks.

Many theorists (Dweck, 1986; Harackievicz, Barron, \& Elliot, 1998; McKeachie, 1961; Pintrich, 2000) have proposed that college students have multiple goals in learning; e.g., satisfying one's need for achievement, enhancing one's self-confidence, obtaining recognition and approval, avoiding flunking-out, obtaining knowledge and skills necessary for a job, confirming that one has studied appropriately, showing that one excels in comparison with other students, avoiding criticism from parents or negative reactions from peers, etc. Thus, it seems likely that intrinsic and extrinsic motivation, rather than being at opposite ends of a single

Corresponding e-mail: aousdannan@yahoo.com, Department of Periodontology, Faculty of Dentistry, The International University for Science and Technology (IUST), Damascus, Syria, orcid.org/0000-0002-2399-6416 
dimension, may be much more complex in their relationships with one another and other variables affecting student achievement. Covington $(1999,2000)$ for example, has shown that working for high grades and avoiding low grades is not incompatible with valuing learning if the students are not failure avoidant and see grades as providing feedback for future improvement.

In general, a moderate level of extrinsic motivation is better than a high level. Higher levels of intrinsic motivation are positively related to grades. Best of all is moderate extrinsic motivation coupled with high intrinsic motivation. These results, like those of Covington $(1999,2000)$ and Pintrich $(2000)$, indicate that extrinsic motivation is not necessarily incompatible with intrinsic motivation.

\section{Situation of the Problem}

To our knowledge, studying the effects of extrinsic motivators on the academic achievement among college students seems to be undermined in the literature.

\section{Aim of the Study}

The aim of the current study was to investigate the effect of a simple tangible reward on the academic achievement of Syrian dental students.

\section{METHOD}

This study took place in the Faculty of Dentistry at the International University for Science and Technology (IUST) in Damascus, Syria. A total of 139 Syrian students aged 19-23 years old, who were assigned to 4 classes attending a course of "Preventive Dentistry" led by one instructor (i.e. Lecturer in Periodontics), were enrolled in the study. They were not informed that they would had been a part of a study in order to avoid any possible bias effect.

According to the Faculty's internal regulations, students had to undergo 2 midterm exams; namely a first exam (FE) and a second exam (SE), as well as a final exam. The interval between FE and SE is usually 4 weeks, and the same instructor (i.e. the researcher himself) was responsible for the preparation of questions for all exams of this course so that an acceptable degree of similarity and homogeneity could had been achieved.

Records of students' marks of both FE and SE were collected, tabulated, and statistically analyzed using a statistical software program (IBM SPSS, Version 21). Descriptive statistics, Analysis Of Variances (ANOVA) test, and paired samples' T-test were applied for data analysis.

\section{Material}

After the completion of FE, and as an award, all students who got full marks (i.e. 20 out of 20) were called during the class time and were given paper-based certificates that had been previously prepared and designed by the researcher. Every certificate was titled as "Certificate of Achievement" with the name of student, the reason of certification (i.e. getting a full mark in FE of Preventive Dentistry course), and the section and Faculty name (Figure 1). 


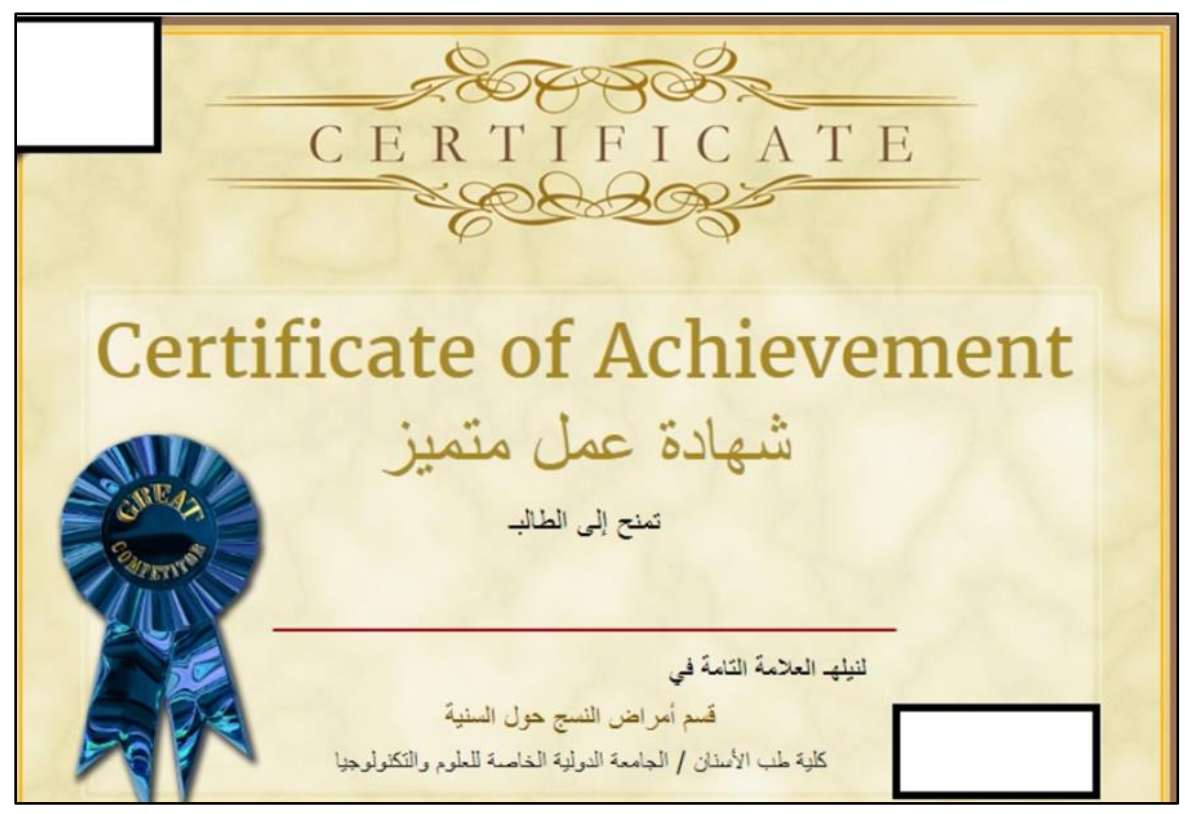

Figure 1. The design of the awarded certificate

All certificates were signed by the instructor. Moreover, during a ceremony-like atmosphere, the rest of students were asked to applaud for their classmates who were given the certificates. The instructor informed the students that such certification would be repeated for the sake of students who would get full marks in $\mathrm{SE}$, and extra 5 marks in the whole course would be awarded to them as well (i.e. who get full marks in both FE and SE).

Four weeks later, SE took place, and the same process of certification for students with full marks was performed.

\section{Data Analyses}

Records of students' marks of both FE and SE were collected, tabulated, and statistically analyzed using a statistical software program (IBM SPSS, Version 21). Descriptive statistics, Analysis Of Variances (ANOVA) test, and paired samples' T-test were applied for data analysis.

\section{FINDINGS}

The sample of this study comprised of 139 students, 85 males $(61.2 \%)$ and 54 females $(38.8 \%)$. The students were distributed in 4 classes; namely class (1) and (2) with 40 students in each class, class (3) included 31 students, and class (4) included 28 students (Table 1).

Table 1. Distribution of students according to gender and class

\begin{tabular}{cccc}
\multicolumn{4}{c}{ Gender } \\
\hline \multirow{4}{*}{ Valid } & Frequency & Percent \\
& Female & 85 & 61.2 \\
& Total & 139 & 38.8 \\
& & & 100.0 \\
\hline \multirow{4}{*}{ Valid } & Class & Frequency & Percent \\
& 1 & 40 & 28.8 \\
& 2 & 40 & 28.8 \\
& 3 & 31 & 22.3 \\
& 4 & 28 & 20.1 \\
& Total & 139 & 100.0 \\
\hline
\end{tabular}


The mean records for FE and SE marks related to each class are demonstrated in table (2).

Table 2. Records of FE and SE marks among classes

\begin{tabular}{ccccccc}
\multicolumn{7}{c}{ Descriptives } \\
\hline \multirow{5}{*}{ Class } & $\mathrm{N}$ & Mean & $\begin{array}{c}\text { Std. } \\
\text { Deviation }\end{array}$ & Minimum & Maximum \\
\cline { 2 - 7 } FE & 1 & 40 & 10.65 & 5.162 & 0 & 20 \\
Marks & 2 & 40 & 9.00 & 4.793 & 1 & 19 \\
& 3 & 31 & 11.45 & 4.850 & 3 & 20 \\
& 4 & 28 & 11.96 & 4.185 & 4 & 20 \\
& Total & 139 & 10.62 & 4.883 & 0 & 20 \\
\multirow{2}{*}{ SE } & 1 & 40 & 14.60 & 4.168 & 0 & 20 \\
& 2 & 40 & 13.83 & 4.437 & 3 & 20 \\
& 3 & 31 & 15.39 & 3.703 & 7 & 20 \\
& 4 & 28 & 15.00 & 3.810 & 6 & 20 \\
\hline
\end{tabular}

$† N$ : Number of students, $\ddagger$ Std. Deviation: Standard Deviation

ANOVA test did not show any statistically significant differences between groups (i.e. classes) neither for FE nor for SE marks (P>0.05) (Table 3).

Table 3. ANOVA test results for comparison of FE and SE marks between classes

\begin{tabular}{|c|c|c|c|c|c|c|}
\hline \multicolumn{7}{|c|}{ ANOVA } \\
\hline & & Sum of Squares & $\mathrm{df}$ & Mean Square & $\mathrm{F}$ & P Value \\
\hline \multirow{3}{*}{ FE Marks } & Between Groups & 177.050 & 3 & 59.017 & 2.559 & $0.058^{*}$ \\
\hline & Within Groups & 3113.742 & 135 & 23.065 & - & - \\
\hline & Total & 3290.791 & 138 & - & - & - \\
\hline \multirow{3}{*}{ SE Marks } & Between Groups & 47.558 & 3 & 15.853 & 0.952 & $0.418^{* *}$ \\
\hline & Within Groups & 2248.730 & 135 & 16.657 & - & - \\
\hline & Total & 2296.288 & 138 & - & - & - \\
\hline
\end{tabular}

$\S d f:$ Degrees of freedom

Comparing FE and SE marks regardless of classes, it was shown that the mean of marks (Mean \pm SD) for FE and SE were (10.62 \pm 4.88$)$ and $(14.63 \pm 4.07)$ respectively. For both FE and SE, all marks ranged between 0 and 20.

According to Paired Samples' T-Test, the difference of means' records for all students between FE and SE on a $95 \%$ confidence level was statistically significant ( $\mathrm{P}=0.0001$ ) (Table 4 ). 
Table 4. Paired Samples' T-Test results for comparison of FE and SE marks

\begin{tabular}{|c|c|c|c|c|c|c|c|c|c|}
\hline \multicolumn{10}{|c|}{ Paired Samples Statistics } \\
\hline \multirow{7}{*}{ Pair } & \multirow{3}{*}{$\begin{array}{c}\text { FE } \\
\text { Marks } \\
\text { SE } \\
\text { Marks }\end{array}$} & \multirow{2}{*}{$\begin{array}{l}\text { Mean } \\
10.62\end{array}$} & $\mathrm{~N}$ & \multicolumn{3}{|c|}{ Std. Deviation } & \multicolumn{3}{|c|}{ Std. Error Mean } \\
\hline & & & 139 & \multicolumn{3}{|c|}{4.883} & \multicolumn{3}{|c|}{0.414} \\
\hline & & 14.63 & 139 & \multicolumn{3}{|c|}{4.079} & \multicolumn{3}{|c|}{0.346} \\
\hline & \multicolumn{9}{|c|}{ Paired Samples Test } \\
\hline & \multicolumn{6}{|c|}{ Paired Differences } & \multirow{3}{*}{$\mathrm{t}$} & \multirow{3}{*}{$\mathrm{df}$} & \multirow{3}{*}{ P Value } \\
\hline & & \multirow[t]{2}{*}{ Mean } & \multirow[t]{2}{*}{$\begin{array}{c}\text { Std. } \\
\text { Deviation }\end{array}$} & $\begin{array}{l}\text { Std. } \\
\text { Error }\end{array}$ & \multicolumn{2}{|c|}{$\begin{array}{c}95 \% \text { Confidence } \\
\text { Interval of the } \\
\text { Difference }\end{array}$} & & & \\
\hline & & & & & Lower & Upper & & & \\
\hline Pair & $\begin{array}{l}\text { FE -SE } \\
\text { Marks }\end{array}$ & -4.014 & 4.275 & 0.363 & -4.731 & -3.297 & -11.071 & 138 & $0.0001^{* * *}$ \\
\hline
\end{tabular}

\section{RESULT, DISCUSSION, AND SUGGESTIONS}

Among college students, intrinsic motivation is motivation in which the task is enjoyable or satisfying in itself; extrinsic motivation is motivation induced by rewards or punishments dependent upon success or failure in the task. In college classes, grades are clearly an extrinsic reward; intrinsic motivation involves interest in the subject matter, enjoyment of challenge, or a sense of making progress and increasing mastery (Lin et al. 2003).

Rewards can be used to influence motivation. By no means are financial rewards the only way to motivate. The literature on reward systems has broadened its scope to include nonfinancial rewards, as these are also important to direct and shape desired behaviors, but usually reward systems refer to the allocation of pay. In the current study, a simple extrinsic motivator (i.e. an honorable awarded certificate) was tested in order to find out its effect on students' achievements; namely on their marks.

No statistically significant differences were found among the four classes neither for FE nor for SE marks. This indicates a logical similarity in the level of students within the classes.

Significantly, the mean of records of SE marks was higher than that of FE marks in a noteworthy way (Figure 2). 


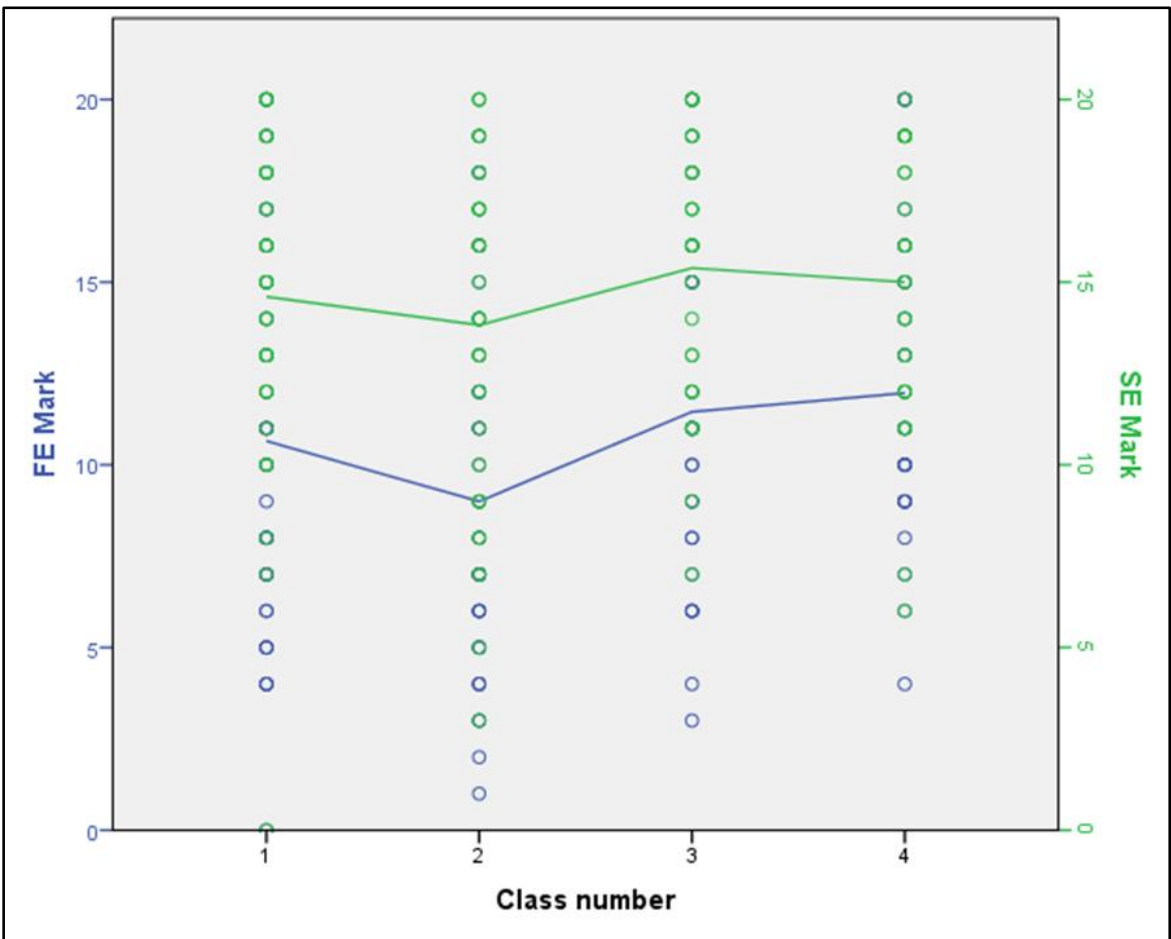

Figure 2. Dual axes scatter-plot graph demonstrating FE and SE marks for all classes

It seems that the idea of a "certificate" as a reward for the students who got full marks in the FE had a positive effect on their motivation, and therefore encouraged them to improve their efforts and show better performance for the SE.

By reviewing the descriptive data, only 8 students had full marks in the FE whereas 13 students had full marks in the SE (data not demonstrated). Though might not be significant, this increase reflects a whole improvement in the students' level of achievement.

It should be emphasized that the students who got full marks in the FE were awarded the certificates without previous knowledge about a reward possibility for their achievements. Informing the students that such certifications would be obtained for full marks in the upcoming SE (i.e. prospectively knowing) made the comparison between FE and SE marks, in terms of students' motivation, more valuable.

Several studies in the literature found that rewards, as extrinsic motivators, in the learning process tended to have negative effects on intrinsic motivation (Festinger and Carlsmith 1959; Deci 1971, 1972b; Lepper et al. 1973), and especially, on the long run (McCullers et al. 1987; Johnson 1999). In the current study, however, although the certificates awarded to students were just of simple paper-based design, and only of moral purposes, the effect of such extrinsic motivator on the students' academic achievements was remarkable.

It could be concluded that a significant improvement of academic achievement in a sample of Syrian dental students was achieved by means of a simple moral reward model in a form of "Certificate of Achievement". Further studies are needed in term of motivation principles for college students, preferably with larger sample size and more controllable factors.

This study highlights the importance of encouragement for college students to produce better academic attainments, even by means of simple extrinsic motivators.

Though the sample of study comprised of college students, not school children, they were so motivated that the improvement of their learning outcome was noteworthy. Higher academic institutions should reconsider an effective activation of reward systems to improve the academic attainments of students. Possible limitation of this study might be the absence of a manipulation check in order to exclude any other factors that might affect the results or have similar effects, so that the tangible motivator would be more valuable and reliable. 


\section{REFERENCES}

Adelman HS, Taylor L. (1990). Intrinsic motivation and school misbehavior: Some intervention implications. Journal of Learning Disabilities. 23(9):541-550.

Amabile TM, Gitomer J. (1984). Children's artistic creativity: Effects of choice in task materials. Personality and Social Psychology Bulletin. 10(2):209-215.

Baranek, L. K. (1996). The effect of rewards and motivation on student achievement. Master Thesis.

Covington, M. V. (1999). Caring about learning: The nature and nurturing of subject-matter appreciation. Educational Psychologist, 34(2), 127-136.

Covington, M. V. (2000). Intrinsic versus extrinsic motivation in schools: A reconciliation. Current directions in psychological Science, 9(1), 22-25.

Deci EL. (1971). Effects of externally mediated rewards on intrinsic motivation. Journal of personality and Social Psychology. 18(1):105.

Deci EL. (1972a). The effects of contingent and non-contingent rewards and controls on intrinsic motivation. Organizational behavior and human performance. 8(2):217-229.

Deci EL. (1972b). Intrinsic motivation, extrinsic reinforcement, and inequity. Journal of personality and social psychology. 22(1):113.

Dweck CS. (1986). Motivational processes affecting learning. American psychologist. 41(10):1040.

Festinger L, Carlsmith JM. (1959). Cognitive consequences of forced compliance. The journal of abnormal and social psychology. 58(2):203.

Harackiewicz JM, Barron KE, Elliot AJ. (1998). Rethinking achievement goals: When are they adaptive for college students and why? Educational psychologist. 33(1):1-21.

Johnson D. (1999). Creating Fat Kids Who Don't Like to Read. Library Talk. 12(4):64-64.

Lepper MR, Greene D, Nisbett RE. (1973). Undermining children's intrinsic interest with extrinsic reward: A test of the" overjustification" hypothesis. Journal of Personality and social Psychology. 28(1):129.

Lin Y-G, McKeachie WJ, Kim YC. (2003). College student intrinsic and/or extrinsic motivation and learning. Learning and individual differences. 13(3):251-258.

McCullers JC, Fabes RA, Moran JD. (1987). Does intrinsic motivation theory explain the adverse effects of rewards on immediate task performance? Journal of Personality and Social Psychology. 52(5):1027.

McKeachie, W. J. (1961). Motivation, teaching methods, and college learning. University of Michigan. (pp. 111-146)

Pintrich PR. (2000). Multiple goals, multiple pathways: The role of goal orientation in learning and achievement. Journal of educational psychology. 92(3):544.

Scott Jr W. (1976). The effects of extrinsic rewards on "intrinsic motivation": A critique. Organizational Behavior and Human Performance. 15(1):117-129.

Spulding CL. (1992). Motivation in the classroom. McGraw-Hill. 